\title{
Desvendando Dinâmicas Locais: o caso da Favela Rio das Pedras
}

SIMONE MONTEIRO ${ }^{1}$

\section{BURGOS, M. (Org.)}

\section{A utopia da Comunidade Rio das Pedras, uma favela carioca.} Rio de Janeiro: Loyola, 2002.

No conjunto das cenas midiáticas recentes do drama vivido pelas populações que vivem nas favelas urbanas, chama a atenção o clima de terror experimentado pelos moradores, decorrente das disputas violentas por territórios e poder entre os grupos que lideram o comércio ilegal de drogas. Na ausência de proteção das instâncias do aparato estatal, moradores sem envolvimento com o tráfico de drogas são obrigados a deixar suas casas, muitas vezes no meio de fogo cruzado provocado pela guerra entre policiais e traficantes ou entre quadrilhas rivais. Essa situação não só indica os poucos avanços em termos de políticas sociais e de segurança pública, como sugere que as rivalidades entre as lideranças das facções criminosas têm fragilizado e, por vezes, eliminado, a possibilidade de identificação dos traficantes, em suas localidades de origem, com as funções de benfeitor e protetor da comunidade, traduzidas pelo poder de tais líderes de estabelecer regras, impor medo e promover atividades de lazer nas localidades dominadas. Cabe ressaltar que tais mecanismos revelam um eficiente ardil de legitimação da dominação violenta.

A despeito das críticas dos moradores acerca das ações ilícitas e de violência dos profissionais do tráfico e das graves implicações sociais da perversa relação de domínio estabelecida por esses atores ${ }^{2}$, parece que o esgarçamento dos apoios fornecidos pelo comércio ilegal nas localidades de origem tem tornado ainda mais visível uma das facetas do abandono social das camadas populares por parte do poder público. Isto não significa que não existam iniciativas bemsucedidas de programas sociais, capitaneados por organizações públicas e da sociedade civil, voltados para a profissionalização e a educação para a cidadania de segmentos urbanos de baixo poder aquisitivo. Todavia, observa-se que essas 
ações são limitadas a um grupo minoritário e que suas repercussões na trajetória de vida dos grupos envolvidos precisam ser avaliadas com maior profundidade.

Essa panorâmica visão acerca da situação das pessoas que hoje vivem nas localidades dominadas pelo tráfico estimula questionamentos em termos das origens, dos mecanismos de manutenção e das perspectivas de mudanças de cenário, bem como indagações sobre as semelhanças e particularidades presentes no conjunto das favelas cariocas. Uma das contribuições das ciências sociais para esta reflexão diz respeito à compreensão da dinâmica ordenadora da vida social dos moradores dessas localidades, possível de ser apreendida a partir de um olhar minucioso e focado. É nesta direção que a proposta da coletânea A utopia da Comunidade Rio das Pedras, uma favela carioca se torna pertinente e relevante.

Ao reunir visões diversas e complementares sobre a favela de Rio das Pedras, a coletânea organizada por Marcelo Burgos nos oferece uma oportunidade ímpar de conhecer as singularidades de uma localidade que, dentre outros aspectos, se apresenta como uma das poucas favelas cariocas capaz de inibir a atuação do comércio ilegal de drogas. Tal característica traz em si uma dimensão peculiar, dada a presença, no imaginário social da cidade, da associação entre favela, tráfico de drogas, pobreza e violência, alimentada pelas recorrentes notícias e imagens divulgadas nos meios de comunicação, citadas no início deste texto. O livro conjuga reflexões resultantes da observação participante e de entrevistas e grupos focais com moradores e lideranças locais realizadas em Rio das Pedras, ao longo do ano de 2001, por professores-pesquisadores e estudantes do Departamento de Sociologia e Política da PUC do Rio de Janeiro. Afinal, o que o livro A utopia da comunidade tem a nos ensinar sobre a concepção e a dinâmica das favelas cariocas, tendo por base o estudo do caso de Rio das Pedras, situada às margens da Lagoa da Tijuca, no bairro de Jacarepaguá? Além da ausência do tráfico, essa localidade, formada no final da década de 1960, é marcada pelo predomínio de imigrantes nordestinos entre os cerca de 40 mil moradores.

Uma característica que se destaca ao longo da leitura dos artigos está relacionada às evidências sobre o poder exercido pela Associação de Moradores na ordenação da vida social em Rio das Pedras. Identificada e legitimada como mediadora entre as demandas da população local e as instituições públicas, as ações da Associação revelam de que modo a ausência de políticas sociais para os segmentos desfavorecidos cria alternativas de organização social. Resta 
saber suas implicações para a vida dos moradores.

$\mathrm{O}$ artigo de Marcelo Burgos é particularmente esclarecedor sobre esse aspecto. Nas suas palavras:

\begin{abstract}
"mesmo sem a presença do tráfico na favela, esse território habitacional costuma abrigar poderosos mecanismos de controle social, que, embora constituam, em muitos casos, cidadelas que protegem parcialmente seus moradores da insegurança social e da escassez absoluta, trazem consigo mecanismos de regulação e participação política, que contribuem para mantê-los afastados da polis" (p. 22).
\end{abstract}

Seu argumento é fundamentado pela análise da especificidade do microssistema favela, em contraposição a um mero aglomerado habitacional, traduzido pela característica da favela de produzir meios de incorporação social de seus habitantes e de regular as relações de vizinhança, atuando como intermediária entre o poder público e os moradores. Todavia, esses mecanismos, exercidos predominantemente pelas Associações de Moradores e, mais recentemente, pelo tráfico de drogas, alimentam as hierarquias sociais, ao restringir a autonomia política dos moradores e o seu acesso aos valores do direito universal e da liberdade.

Marcelo Burgos avança e enriquece a discussão, ao propor que o tema favela seja abordado a partir da sua relação com o contexto político nacional de transição democrática. Para tanto, elenca cinco indagações que deveriam ser exploradas nos estudos sobre a temática, quais sejam: 1) cultura política e cidadania; 2) associativismo e mobilização popular; 3) avaliação de políticas públicas; 4) articulação entre intelectuais; 5) favela e a lógica do mercado. A partir de tais questionamentos, o autor reflete sobre a estrutura socioespacial e política de Rio das Pedras. Sua análise revela de que modo o crescimento da favela está vinculado ao domínio da Associação de Moradores na definição, estratificação e regulação da ocupação territorial da localidade, tendo por base o predomínio de valores tradicionais (centrados nos vínculos interpessoais e nas concepções de troca e reciprocidade), em oposição aos valores dominantes do individualismo moderno. Passamos a compreender como as diversas funções de poder da Associação, no plano do controle social, da autoridade moral, da mediação e arbitragem de conflitos (pessoais, jurídicos...) foram sendo consolidadas ao longo dos anos, sob a cumplicidade do poder público. A amplitude de tais ações é descrita como um novo clientelismo, caracterizado por um 
"sistema de trocas" entre os membros da própria localidade, sendo assim mais autônomo em relação aos mecanismos tradicionais exteriores a ela. $\mathrm{O}$ autor salienta que a concepção de bem público não se apóia na noção moderna de direito individual e cidadania, mas nos laços de solidariedade e coesão dos segmentos que constituem os espaços da favela, a despeito de suas assimetrias. Nas suas palavras:

\footnotetext{
"Essa forma de construção do público, como via às avessas de produção da cidadania, é estranha à matriz liberal clássica. Remonta, talvez, à nossa tradição ibérica, onde o território se articula com a idéia do bem público para se opor à autonomia e ao individualismo" (p. 88-89).
}

As particularidades de aspectos históricos e socioeconômicos, destacadas nos artigos seguintes, vão compondo o quebra-cabeça acerca da formação e dinâmica da vida dos moradores de Rio das Pedras. Nesta perspectiva, o trabalho de Yuri Kasahara esclarece que o rápido crescimento populacional da favela de Rio das Pedras, quando comparado aos padrões de evolução da população do município do Rio de Janeiro, pode ser entendido a partir da expansão da região da Barra da Tijuca e de Jacarepaguá. Tal expansão é ainda demonstrada por indicadores relativos à atividade imobiliária, à arrecadação de impostos e ao índice de desenvolvimento humano. Segundo o autor, o surgimento de uma favela recente e muito populosa, em uma região com poder aquisitivo e demanda por mão-de-obra barata, revela a previsibilidade desse processo.

O fenômeno da favelização é retomado e aprofundado por Antonio Carlos Alkimim, por meio da caracterização da evolução das favelas no Rio de Janeiro desde seu surgimento. Além de assinalar aspectos mais gerais do fenômeno, vinculados aos fluxos migratórios e ao agravamento das desigualdades sociais, o autor faz uma análise de Rio das Pedras centrada na conformação e segmentação socioespacial da favela e no papel do associativismo, já assinalado como uma dimensão peculiar daquela localidade. Para tal aplica um índice de nível socioeconômico nas doze áreas da favela, capaz de revelar as relações entre tempo de moradia, status socioeconômico, naturalidade (origem), cor e grau de associativismo (vínculo e aprovação à Associação de Moradores).

A compreensão das implicações do associativismo para as favelas é iluminada pelo artigo seguinte, de Luiz Cleber Farias, referente à descrição do processo de surgimento e fechamento da Associação de Comércio e Indústria 
de Rio das Pedras (ACIRPE). Após traçar um panorama sobre o dinâmico mercado consumidor nas favelas, não regulado pelo estado, o autor descreve o comércio local nas diferentes áreas de Rio das Pedras, assim como o surgimento e insucesso do projeto da ACIRPE. O projeto tinha como meta proteger os pequenos e microempreendedores da localidade frente à competição externa, a partir da regulamentação e da legalização. Seu fracasso é atribuído à resistência da Associação de Moradores, à falta de interesse dos comerciantes locais e à inexperiência dos organizadores na associação de interesses.

Outro aspecto relativo à falta de regulação estatal é abordado pelo trabalho de Aparecida Camargo, sobre a presença de várias creches irregulares em Rio das Pedras, muitas das quais funcionando em condições precárias. Os obstáculos para a legalização ficam mais claros pela descrição das exigências e do tempo necessário para sua efetivação. Contribuem ainda para a clandestinidade: a falta de pressão social e visibilidade em relação às obrigações do poder público com a educação infantil e as necessidades dos pais de terem alguém para tomar conta das crianças. A autora assinala que, em vez da formalização das creches irregulares, caberia a universalização da rede pública de educação infantil.

Os demais textos da coletânea agregam novas peças ao quebra-cabeça de Rio das Pedras, por meio de investigações das percepções e práticas dos atores sociais, de seus residentes acerca de diferentes temáticas. Nesta direção, Afrânio Silva reflete sobre a visão de violência dos moradores. O autor sugere que o superdimensionamento da tranquiilidade de Rio das Pedras, vinculado à ausência do tráfico, obscurecem a conscientização das formas autoritárias de poder vigentes e as perspectivas dos benefícios de direitos de cidadania. Mais uma vez, ressalta-se o papel de autoridade moral conferida pela população local à Associação de Moradores por sua responsabilidade na manutenção da ordem, entendida em larga medida pela ausência do tráfico de drogas. Afrânio conclui: "o que conta é mais o desejo de proteção que o de autonomia" (p. 166).

A forte presença da imigração nordestina em Rio das Pedras torna relevante a abordagem de Paulo Roberto Patrocínio, Érica Araújo e Fernando Silva, acerca das representações das culturas nordestina e carioca entre professores da rede pública da localidade. Foi constatado que a origem nordestina está associada à rigidez de princípios e valorização do trabalho e da educação, com perspectiva de mobilidade social. De forma contraposta, o carioca é identificado com a "liberdade de valores" e a falta de compromisso com a 
escolarização. Tais dados suscitam indagações sobre a origem das pessoas entrevistadas e das implicações da construção da identidade do nordestino e do carioca, que poderiam ser exploradas posteriormente. Ainda dentro da análise sobre a formação de estereótipos, Marcelo Ferreira estabelece as conexões entre turismo e favela, para, em seguida, nos levar para um tour em Rio das Pedras, a partir de sua experiência profissional como guia de turismo local.

No último artigo da coletânea, Laura Moutinho nos revela as formas de interação social em Rio das Pedras, destacando as especificidades da lógica das relações de gênero e de cor / raça. A autora encontra pontos comuns com outros estudos referentes ao predomínio de um padrão tradicional entre segmentos populares urbanos, como as relações assimétricas de gênero e o valor atribuído à família. Todavia, destaca nuanças nesse padrão em Rio das Pedras, exemplificado pela presença de um ethos viril mais cavalheiresco, que se distancia do modelo sexual agressivo. Outro aspecto abordado diz respeito à não-identificação de narrativas nas quais a cor negra se associa à violência. As especificidades assinaladas são atribuídas à ausência do tráfico e à falta de disputas por territórios marcadas por questões raciais e regionais.

Não tenho dúvida sobre os ensinamentos proporcionados pelos argumentos apresentados pelos autores e suas contribuições na compreensão da concepção e dinamismo das favelas cariocas, em termos de seus elementos particulares e universais. Ademais, a coletânea tem a capacidade de inspirar novas análises acerca de um tema atual que de várias maneiras integra a vida cotidiana da população do Rio de Janeiro. 


\section{Referências}

FONSECA, C. Bandidos e mocinhos: antropologia da violência no cotidiano. Humanas: Revista da IFCH/UFRGS. Porto Alegre, v. 1, n. 2, p. 67-89, jul./ dez. 1993.

MONTEIRO, S. Qual prevenção! Aids, sexualidade e gênero em uma favela carioca. Rio de Janeiro: Fiocruz, 2002.

ZALUAR, A. A máquina e a revolta: as organizações populares e o significado da pobreza. São Paulo: Brasiliense, 1985.

Condomínio do diabo. Rio de Janeiro: Revan, 1994.

\section{NOTAS}

${ }^{1}$ Ph.D. em Saúde Pública, chefe e pesquisadora do Laboratório de Educação em Ambiente e Saúde (Departamento de Biologia - Instituto Oswaldo Cruz, da Fundação Oswaldo Cruz. Email: msimone@ioc.fiocruz.br

${ }^{2}$ Ver Monteiro (2002), Fonseca (1993) e Zaluar (1985, 1994). 